\title{
Clinical Utility of Antibiotic against Uropathogen Isolated at a Tertiary Care Hospital of Dhaka City
}

\author{
Rashida Akter Khanam ${ }^{1, *}$, Ahmed Sharif ${ }^{2}$, Ishrat Sharmin ${ }^{3}$, Soma Sarker $^{1}$, Hosne Jahan ${ }^{1}$, Md. Abdullah Yusuf ${ }^{4}$ \\ ${ }^{1}$ Department of Microbiology, Shaheed Suhrawardy Medical College, Dhaka, Bangladesh \\ ${ }^{2}$ Department of ENT, Mugda Medical College, Dhaka, Bangladesh \\ ${ }^{3}$ Department of Pathology with Microbiology, Dhaka Dental College, Dhaka, Bangladesh \\ ${ }^{4}$ Department of Microbiology, National Institute of Neurosciences \& Hospital, Dhaka, Bangladesh \\ *Corresponding author: rafsancosmo@gmail.com
}

\begin{abstract}
Background: The antibiotic sensitivity pattern of uropathogenic bacteria is varied with different frequency. Objective: The purpose of the study was to determine the pattern of antibiotic sensitivity against uropathogens isolated from a tertiary care hospital of Dhaka City. Methodology: A cross-sectional study was conducted in the Department of Microbiology at Shaheed Suhrawardy Medical College, Dhaka, Bangladesh during period of January 2016 to December 2016. Among 307 consecutive urine samples were collected from patients of UTI in the microbiology laboratory. Samples were mid-stream urine specimens obtained by clean catch method received from various outpatient departments and inpatient wards were transported to the microbiology laboratory in sterile leak proof container were processed immediately. Bacteria were isolated and identified by standard laboratory procedure. Results: Of the 307 urine samples processed 170(55.4\%) gave significant growth of pathogens. The prevalence of UTI is high among females $(58.2 \%)$ than males $(41.8 \%)$. The commonest isolates were Escherichia coli (71.2\%), Pseudomonas (12.4\%), Staphylococcus aureus (10.6\%), Acinotobactor (4.1\%) and Klebsiella (1.8\%). Majority (92.4\%) of (uropathogens) isolates were found to be MDR. Conclusion: The study revealed that $E$. coli is the predominant uropathogens of UTIs.
\end{abstract}

Keywords: antimicrobial agents, bacteriuria, E.coli, Urinary Tract Infection

Cite This Article: Rashida Akter Khanam, Ahmed Sharif, Ishrat Sharmin, Soma Sarker, Hosne Jahan, and Md. Abdullah Yusuf, "Clinical Utility of Antibiotic against Uropathogen Isolated at a Tertiary Care Hospital of Dhaka City." American Journal of Microbiological Research, vol. 6, no. 2 (2018): 63-66. doi: 10.12691/ajmr-6-2-5.

\section{Introduction}

Urinary tract infection (UTI) represents one of the most common diseases encountered in medical practice today, occurring from the neonate to the geriatric age group. [1] It is also the most common nosocomial infection, accounting for up to $40 \%$ of all nosocomial infections. [2] UTI is particularly responsible for discomfort in elderly patients, representing a risk of bacteremia, septic shock, respiratory distress syndrome and death. [3] Even though several different microorganisms can cause UTI, including bacteria, protozoan parasites, fungi and viruses. Bacteria are the major causative organisms and they account for more than $95 \%$ of UTI cases. [4] Bacteria causing UTI are generally of fecal origin. [5.6] Among the bacteria, Escherichia coli (E. coli) is the most common etiological agent, accounting for $75-90 \%$ of UTI in both outpatients and inpatients. ${ }^{7}$ Complicated UTI exhibits a broader bacterial spectrum as the cause of infection. [7]

In almost all cases of UTI, empirical antimicrobial treatment is initiated before the laboratory results of urine culture and sensitivity are available. Thus, antibiotic resistance may increase in uropathogens due to frequent misuse of antibiotics. [7] In addition, the extensive use of antibiotics, for infections outside the urinary tract, would alter the antibiotic susceptibility pattern of the intestinal bacteria that are generally implicated as uropathogens. [6] Increasing antimicrobial resistance complicates uncomplicated UTI treatment by increasing patient morbidity, costs of reassessment and retreatment and use of broader-spectrum antibiotics. [8] Patterns of antibiotic resistance in a wide variety of pathogenic organisms vary even over short periods of time. Periodic evaluation of antibacterial activity is needed to update this information. [9] For effective treatment and control of UTI in a particular area/hospital, a good knowledge of the antibiotic sensitivity pattern of the causative agents in that area/hospital is of ultimate importance $[6,10]$.

This study was carried out to analyze various uropathogens and their antimicrobial susceptibility pattern in a tertiary care hospital, which assist in selecting the most appropriate antibiotic therapy in treatment of Urinary Tract Infection.

\section{Methodology}

A cross-sectional study was conducted in the Department of Microbiology at Shaheed Suhrawardy Medical College, Dhaka during period of January 2016 to 
December 2016 for a period of one year. Patients diagnosed clinically as urinary tract infection (UTI) on the basis of symptoms at any age with both sexes were taken as study population. Samples were mid-stream urine specimens obtained by clean catch method received from various outpatient departments and inpatient wards were transported to the microbiology laboratory in sterile leak proof container were processed immediately. Bacteria were isolated and identified by standard laboratory procedure. Specimens were examined under microscope and those specimens showed pus cell 5 or more were inoculated on Blood agar, McConkey Agar plates, and on Chromogenic media which were incubated aerobically at $37^{0} \mathrm{C}$ overnight. Antimicrobial sensitivity testing was performed using Kirby Bauer disc diffusion method as described by the Laboratory Standard Institute. ${ }^{11}$ Interpretation as Sensitive or Resistant was done on the basis of the diameters of zone of inhibition of bacterial growth as recommended by disc manufacturer. The antibiotics used for susceptibility testing were Amikacin $(30 \mu \mathrm{gm})$, Gentamycin $(10 \mu \mathrm{gm})$, Cefotaxim $(30 \mu \mathrm{gm})$, Ciprofloxacin

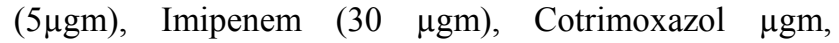
Azythromycin $(15 \mu \mathrm{gm})$, Amoxycillin $(30 \mu \mathrm{gm})$, Cephalexin

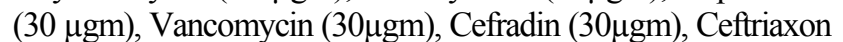
(30 $\mu \mathrm{gm})$, Nitelmycin(30 $\mathrm{gm})$, Ampicillin $(25 \mu \mathrm{gm})$, Erythromycin $(15 \mu \mathrm{gm})$, Pefloxacin $\mu \mathrm{gm}$, Cefuroxim

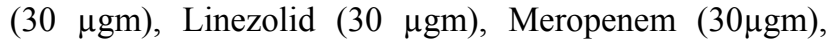
Cloxacillin $(20 \mu \mathrm{gm})$, Ceftazidim $(30 \mu \mathrm{gm})$, Amoxiclave

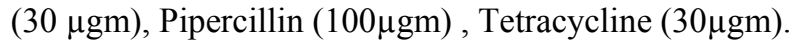

\section{Results}

Out of 307 urine samples majority were given the significant growth of bacteria which was $170(55.4 \%)$ cases (Table 1). In the demographic profile of UTI the patients were between 1 and 78 years of age. The prevalence of UTI was high among females (58.2\%) than males $(41.8 \%)$. The commonest isolates were Escherichia coli $(71.2 \%$,$) , Pseudomonas (12.4 \%)$, Staphylococcus aureus (10.6\%), Acinotobactor (4.1\%) and Klebsiella $(1.8 \%)$.

Table 1. Culture Positivity of Study Population $(n=300)$

\begin{tabular}{lcc}
\hline Isolated Organism & Frequency & Percent \\
\hline No growth & 137 & 44.6 \\
Growth & 170 & 55.4 \\
Total & 307 & 100.0 \\
\hline
\end{tabular}

Table 2. Demographic characteristics of the study subjects

\begin{tabular}{ccccccc}
\hline \multirow{2}{*}{ Age in years } & \multicolumn{2}{c}{ Male } & \multicolumn{2}{c}{ Female } & \multicolumn{2}{c}{ Total } \\
\cline { 2 - 7 } & No & \% & No & $\%$ & No & $\%$ \\
\hline $1-20$ & 18 & 25.4 & 26 & 26.3 & 44 & 25.9 \\
$21-40$ & 21 & 29.6 & 35 & 34.4 & 56 & 32.9 \\
$41-60$ & 20 & 28.2 & 26 & 26.3 & 46 & 27.1 \\
$>60$ & 12 & 16.9 & 12 & 12.1 & 24 & 14.1 \\
\hline Total & 71 & 41.7 & 99 & 58.3 & 170 & 100.0 \\
\hline
\end{tabular}

Table 3. Rate of Isolated Uropathogenic Bacteria

\begin{tabular}{lcc}
\hline Types of organism & Number & Percentage (\%) \\
\hline E.Coli & 121 & 71.2 \\
Psudomonus & 21 & 12.4 \\
Staphylococcus & 18 & 10.6 \\
Klebsila & 3 & 1.8 \\
Acinatobactor & 7 & 4.1 \\
\hline
\end{tabular}

Table 4. Antibiotic sensitivity and Resistance pattern of isolated organisms in UTI

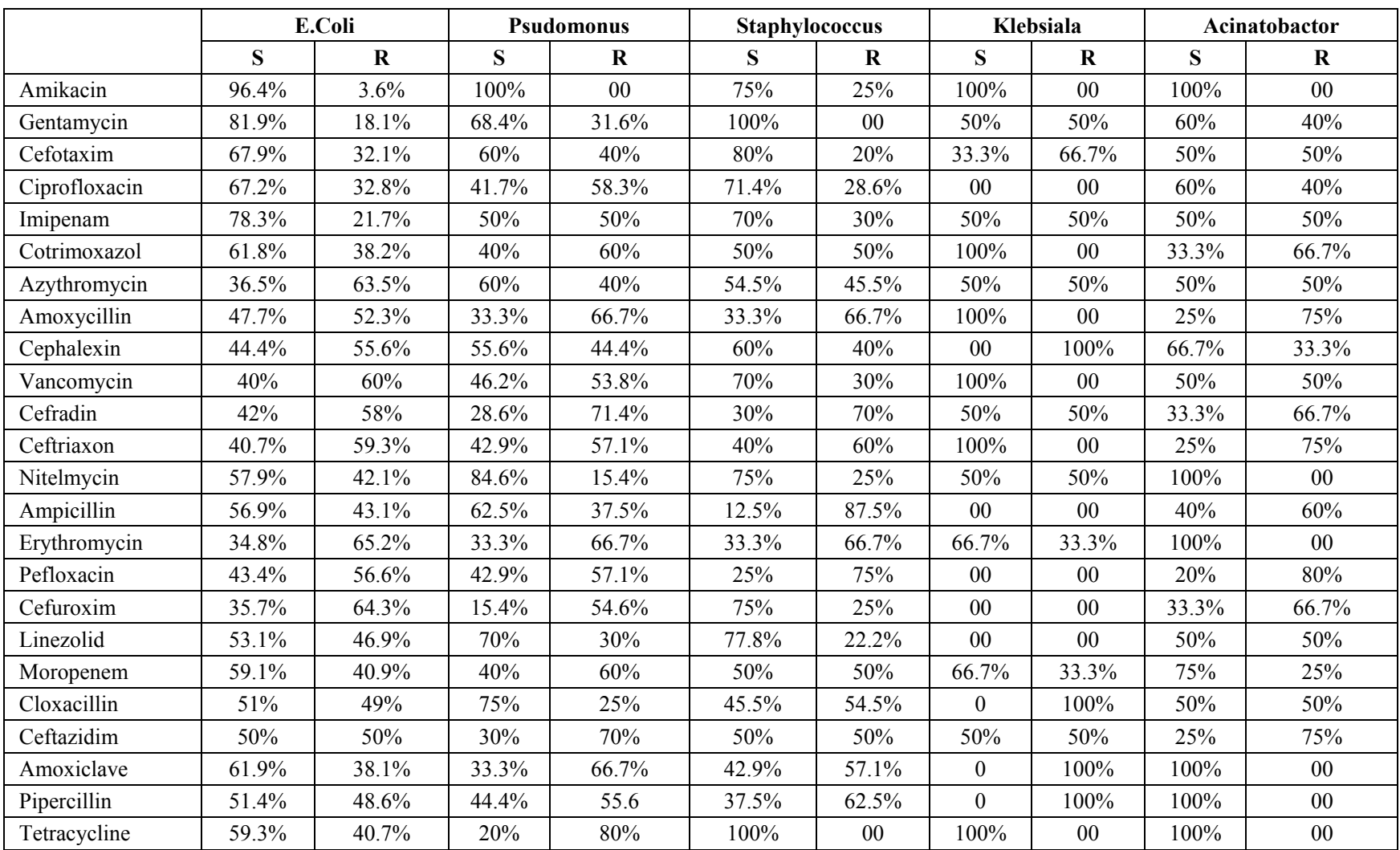


Table 5. Pattern of Multi drug resistant Uropathogenic Bacteria

\begin{tabular}{|l|c|c|c|c|}
\hline Isolated organisms & \multicolumn{2}{|c|}{$\begin{array}{c}\text { MDR } \\
(\mathbf{n}=157)\end{array}$} & \multicolumn{2}{c|}{$\begin{array}{c}\text { Non MDR } \\
(\mathbf{n}=\mathbf{1 3})\end{array}$} \\
\hline E. Coli & \multicolumn{2}{|c|}{$113(93.4 \%)$} & 8 & 6.6 \\
\hline Psudomonus & 18 & 85.7 & 3 & 14.3 \\
\hline Staphylococcus & 18 & 100 & 0 & 00 \\
\hline Klebsila & 3 & 66.7 & 1 & 33.3 \\
\hline Acinatobactor & 6 & 85.7 & 1 & 14.3 \\
\hline Total & 157 & 92.4 & 13 & 7.6 \\
\hline
\end{tabular}

The antimicrobial potency and spectrum for 24 selected antimicrobial agents of different classes. E. coli showed high sensitivity to amikacin (96.4\%), gentamycin $(81.9 \%)$ and imipenem $(78.3 \%)$ followed by cefotaxim $(67.9 \%)$, ciprofloxacin (67.2\%) and amoxaclave (61.9\%). Pseudomonas showed highest sensitivity to amikacin (100\%) followed by cloxacilin (75\%), linezolid (70\%) and gentamycin (68.4\%). Staphylococcus aureus showed highest sensitivity to gentamycin and tetracycline (100\%) followed by cefotaxim $(80 \%)$. amikacin, contrimoxazol, amoxycillin, vancomycin, ceftriaxon and tetracycline are $100 \%$ sensitive against Klebsiella followed by erythromycin (66.7\%) and meropenem (66.7\%). acinatobactor showed highest sensitivity to amikacin, nitelmycin and erythromycin, amoxiclave, pipercillin and tetracyclin $(100 \%)$ followed by Cephalexin $(66.7 \%)$, Gentamycin and Ciprofloxacin (60\%). Majority (92.4\%) of Enterobacteriaceae isolates were found to be MDR.

Multi Drug Resistant (MDR) is defined as isolates resistant to at least 3 classes of drugs.

\section{Discussion}

The study observes that the prevalence of UTI is high among females $(58.3 \%)$ than males $(41.7 \%)$. Females of the reproductive age group (21-40 years) constituted $29.6 \%$ of the total patients with UTI. It has been reported that adult women have a higher prevalence of UTI than men, principally due to anatomical and physical factors. [12] Among males an increased prevalence of UTI was recorded in elderly age group $41-78(45.1 \%)$ than young $(25.4 \%)$. This is probably because with advancing age, the incidence of UTI increases in men due to prostate enlargement and neurogenic bladder. [13]

In this study out of all samples majority (55.4\%) are growth positive. The reason is that the suppurative infection of the skin, ear, and eye are common occurrences in hospitalized patients as well as in the outpatients department. Furthermore wound infection is regarded as the most common nosocomial infection among surgical patients. [14] It has been associated with increased trauma care, prolonged hospitals stay, and treatment. [15]

The study demonstrates that E.coli remain the leading uropathogen being responsible for $71.2 \%$ of UTI. This is in consistence with findings of other studies in which $E$. coli was the most frequently reported isolate from patients with UTIs. [16] Following E.coli our study shows Pseudomonas (12.4\%), Staphylococcus (10.6\%), Acinatobacter (4.1\%) and Klebsiela (1.8\%) as the other common uropathogens. Our findings are in accordance with a study by Dias et al. [17]

In this study the antimicrobial potency and spectrum for 24 selected antimicrobial agents of different classes. E. coli showed high sensitivity to amikacin (96.4\%), gentamycin $(81.9 \%)$ and imipenam $(78.3 \%)$ followed by cefotaxim (67.9\%), ciprofloxacin $(67.2 \%)$ and amoxiclave, (61.9\%). Pseudomonas showed highest sensitivity to amikacin (100\%) followed by cloxacilin (75\%), linezolid $(70 \%)$ and gentamycin (68.4\%). Staphylococcus aureus showed highest sensitivity to Gentamycin and Tetracycline $(100 \%)$ followed by Cefotaxim (80\%). Amikacin, contrimoxazol, amoxycillin, vancomycin, ceftriaxon and tetracycline are $100 \%$ sensitive against Klebsiella followed by Erythromycin (66.7\%) and Meropenem (66.7\%). Acinatobactor showed highest sensitivity to Amikacin, Nitelmycin and Erythromycin, Amoxiclave, Pipercillin and Tetracyclin (100\%) followed by Cephalexin (66.7\%), Gentamycin and Ciprofloxacin (60\%). Majority (92.4\%) of Enterobacteriaceae isolates were found to be MDR. This finding is comparable to Shilpi et al. [18] in Bangladesh who has found that members of Enterobacteiacaee variably sensitive to different antibiotics. Similar susceptibility pattern was also reported by Sultana et al. [19]

The overall prevalence of MDR among enterobacteriaceae isolates identified from patients with symptomatic UTI was $92.4 \%$ which is similar with the results from previous study in Gondar (85.5\%), Eshetie $(87.4 \%)$ and Mozambique $(88.2 \%)[20,21,22]$ while it was higher than reports from other study in Ethiopia: Gondar (68\%), and Dessie $(74.6 \%)[23,24]$ and many other countries, such as USA $(19.1 \%)$, Belgium $(62 \%)$, and Italy $(62 \%)$, Nepal $(40.1 \%, 64.04 \%)$. [25,26,27,28,29] However, it was lower than reports from different parts of Ethiopia such as Gondar (93.5\%), Bahirdar (95.6\%), and Jimma (100\%). $[30,31,32]$ The variation in prevalence of MDRE isolates could be due to increase trend of MDR strains with time, difference in study period and study population.

The present study showed that, Staphylococcus (100\%) and E.coli $(93.4 \%)$ were found to be the principal MDR isolates. Although the rate of proportion of MDR is different in different area similar group of bacteria were reported in Bahirdar, Ethiopia E.coli $(94.6 \%)$ \& K. pneumoniae (80\%) [31] and Nepal, E.coli (74\%) and $K$. pneumoniae $(44 \%)$ and Dakar, E. coli and $K$. pneumoniae (89\%) [33] were the predominant MDR uropathogens. [30] These pathogens are the most common isolates in both hospital and community acquired urinary tract infections. Besides, these bacteria are frequently difficult to treat because of both their intrinsic and acquired resistance to multiple groups of antimicrobial agents. $[3,4]$

\section{Conclusion}

In this study, culture positive rate for uropathogens was high, with the majority coming from adult female patients. E.coli was the most common etiological agent and remains susceptible to Amikacin. Findings of present study suggest that the further regular monitoring is required for patient management and susceptibility pattern 
of urinary pathogens also very important for optimal therapy of patients with UTI.

\section{References}

[1] Tambekar DH, Dhanorkar DV, Gulhane SR, Khandelwal VK, Dudhane MN. Antibacterial susceptibility of some urinary tract pathogens to commonly used antibiotics. Afr J Biotechnol. 2006; 5: $1562-5$.

[2] Szasz M, Lehotkai N, Kristóf K, Szabó D, Nagy K. Prevalence and antimicrobial resistance of uropathogens in different inpatient wards. Acta Microbiol Immunol Hung. 2009; 56: 375-87. [PubMed].

[3] Shaikh D, Ashfaq S, Shaikh K, Shaikh M, Naqvi BS, Mahmood ZA, et al. Studies on resistance/sensitivity pattern of bacteria related with urinary tract infections. Med J Islamic Wld Acad Sci. 2005; 15: 129-33.

[4] Arjunan M, Al-Salamah AA, Amuthan M. Prevalence and antibiotic susceptibility of uropathogens in patients from a rural environment, Tamil Nadu. Am J Infect Dis. 2010; 6: 29-3.

[5] Chamberlain NR. Urinary Tract Infections. Urethritis, Cystitis, Pyelonephritis. [Last accessed on 2012 Dec 02]. Available from: http://www.Kcom/edu/faculty/Chamberlain/website.Lectures/lectu re.

[6] Uwaezuoke JC, Ogbulie JN. Antibiotic sensitivity pattern of urinary tract pathogens in port- Harcourt, Nigeria. J Appl Sci Environ Mgt. 2006; 10: 103-7.

[7] Kashef N, Djavid GE, Shahbazi S. Antimicrobial susceptibility patterns of community-acquired uropathogens in Tehran, Iran. J Infect Dev Ctries. 2010; 4: 202-6. [PubMed]

[8] Aypak C, Altunsoy A, Düzgün N. Empiric antibiotic therapy in acute uncomplicated urinary tract infections and fluoroquinolone resistance: A prospective observational study. Ann Clin Microbiol Antimicrob. 2009; 8: 27. [PMC free article] [PubMed]

[9] Gupta V, Yadav A, Joshi RM. Antibiotic resistance patterns in uropathogens. Indian J Med Microbiol. 2002; 20: 96-8. [PubMed]

[10] Kamat US, Fereirra A, Amonkar D, Motghare DD, Kulkarni MS. Epidemiology of hospital acquired urinary tract infections in a medical college hospital in Goa. Indian J Urol. 2009; 25: 76-80.

[11] National Committee for Clinical Laboratory Standards: Methods for Disk Susceptibility Tests for Bacteria That Grow Aerobically. NCCLS Document M2-A7. Wayne, National Committee for Clinical Laboratory Standards 7th edition. 2000

[12] Akram M, Shahid M, Khan AU. Etiology and antibiotic resistance patterns of community acquired urinary tract infections in JNMC Hospital, Aligarh, India. Ann Clin Microbiol Antimicrob 2007; 6: 6.

[13] Das R, Chandrasekhar TS, Joshi HS, Gurung M, Shreshtha N, Shivananda PG. Frequency and susceptibility profile of pathogens causing urinary tract infections at a tertiary care hospital in western Nepal. Singapore Med J 2006; 474: 281-5.

[14] Rice L. B. Antimicrobial resistance in gram-positive bacteria. The American Journal of Medicine. 2006; 119 (6, supplement 1): S11-S19.

[15] Misic A. M., Gardner S. E., Grice E. A. The Wound Microbiome: modern approaches to examining the role of microorganisms in impaired chronic wound healing. Advances in Wound Care. 2014; 3(7): 502-510.

[16] Dimitrov TS, Udo EE, Emara M, Awni F, Passadilla R. Etiology and antibiotic susceptibility patterns of community acquired urinary tract infections in a Kuwait Hospital. Med Princ Pract 2004; 13: 334-9.

[17] Dias Neto JA, Martins AC, Tiraboschi RB, Domingos AL, Cologna AJ, Paschoalin EL, et al. Community acquired urinary tract infection: Etiology and bacterial susceptibility. Acta Cir Bras 2003; 18(Supp15): 33-6. 16

[18] Shilpi T, Ahmed MN, Huq SMA, Baul SK, Khatun M: Isolation of Bacteria Causing Urinary Tract Infections and their Antibiotic Susceptibility Profile at Anwer Khan Modern Medical College Hospital. Anwer Khan Modern Med Coll J. 2013; 4(2): 23-27.

[19] Sultana A, Rahman K, Manjula S. Clinical update and treatment of lactation insufficiency. Med J Islamic World Academy Sci 2013; 21(1): 19-28.

[20] Tessema B, Kassu A, Mulu A, Yismaw G. Pridominant isolates of urinary tract pathogens and their antimicrobial susceptiblity patterns in Gondar University Teaching Hospital, nothwest Ethiopia. Ethiop Med J. 2007; 45(1): 61-7.

[21] Setegn Eshetie, Chandrashekhar Unakal, Aschalew Gelaw, Birhanu Ayelign, Mengistu Endris, and Feleke Moges. Multidrug resistant and carbapenemase producing Enterobacteriaceae among patients with urinary tract infection at referral Hospital, Northwest Ethiopia. Antimicrob Resist Infect Control. 2015; 4: 12.

[22] van der Meeren BT, Chhaganlal KD, Pfeiffer A, Gomez E, Ferro JJ, Hilbink M, et al. Extremely high prevalence of multi-resistance among uropathogens from hospitalised children in Beira, Mozambique. S Afr Med J. 2013; 103(6): 382-6.

[23] Moges F, Genetu A, Mengistu G. Multi drug resistance in urinary pathogens at Gondar Hospital, Ethiopia. E Afr Med J. 2002; 79(3): 140-2.

[24] Kibret M, Abera B. Antimicrobial susceptibility patterns of E. coli from clinical sources in Northeast Ethiopia. Afr Health Sci. 2011; 11(3): 40-5.

[25] Khawcharoenporn T, Vasoo S, Singh K. Urinary tract infections due to multidrug-resistant Enterobacteriaceae: prevalence and risk factors in a Chicago Emergency Department. J Emerg Med. 2013; 2013: 258517 .

[26] Huang T-D, Berhin C, Bogaerts P, Glupczynski Y. In vitro susceptibility of multidrug-resistant Enterobacteriaceae clinical isolates to tigecycline. J Antimicrob Chemother. 2012; 67(11): 2696-9.

[27] Luca A, Migliavacca R, Regattin L, Brusaferro S, Raglio A, Pagani L, et al. Prevalence of urinary colonization by extended spectrum-beta-lactamase Enterobacteriaceae among catheterised inpatients in Italian long term care facilities. BMC Infect Dis. 2013; 13(1): 124.

[28] Baral P, Neupane S, Marasini BP, Ghimire KR, Lekhak B, Shrestha B. High prevalence of multidrug resistance in bacterial uropathogens from Kathmandu, Nepal. BMC Res Notes. 2012; $5(1): 38$.

[29] Thakur SPN, Sharma M. Prevalence of multidrug resistant Enterobacteriaceae and extended spectrum $\beta$ lactamase producing Escherichia Coli in urinary tract infection. Res J Pharm Biol Chem Sci. 2013; 4(2): 1615

[30] Agersew AMD, Meseret A, Mucheye G. Uropathogenic bacterial isolates and their antimicrobial susceptibility patterns among HIV/AIDS patients attending Gondar University Specialized Hospital Gondar, Northwest Ethiopia. J Microb Res Rev. 2013; 1(4): 42-51

[31] Biadglegne F, Abera B. Antimicrobial resistance of bacterial isolates from urinary tract infections at Felge Hiwot Referral Hospital, Ethiopia. Ethiop J Health Dev. 2009; 23: 236-8.

[32] Beyene G, Tsegaye W. Bacterial uropathogens in urinary tract infection and antibiotic susceptibility pattern in JimmaUniversity specialized hospital, Southwest Ethiopia. Ethiop J Health Sci. 2011; 21(2): 141-6.

[33] Dromigny JA, Ndoye B, Macondo EA, Nabeth P, Siby T, PerrierGros-Claude JD. Increasing prevalence of antimicrobial resistance among Enterobacteriaceae uropathogens in Dakar, Senegal: a multicenter study. Diagn Microbiol Infect Dis. 2003; 47(4): 595-600. 